\title{
The Gametophytes and Fertilization in Laminaria and Chorda. (Preliminary Account.)
}

BY

\section{J. LLOYD WILLIAMS.}

T $\mathrm{N}$ the study of artificial cultures of germinating spores of members of 1 this group of Algae, one always observed the presence of a much smaller brown alga along with the undoubted cells or cell-chains that gave rise to the laminarian plants. As the terminal cells of the branches of the smaller alga were frequently found to be empty, the idea suggested itself that they were the antheridia of the male gametophyte.

Until recently all attempts at verifying this conjecture by observing the liberation of the contents and the process of fertilization failed. To Sauvaugeau belongs the credit of finding the first piece of evidence in favour of the correctness of the above suggestion. Although he, also, failed ta find actual liberation of male gametes and fertilization, he was lucky enough to find in Saccorrhiza abnormal cases of germination of zoospores within liberated but unripe sporangia. In these cases the resulting growths were of two kinds, and similar in every respect to the two always found in normal cultures. This made it almost certain that the smaller alga, which had appeared so puzzling, was also derived from zoospores of Saccorrhiza, and consequently must be the male gametophyte. The writer of this article did not feel himself justified in publishing his own detailed study of the group until he had seen and studied the actual liberation of antherozoids and the process of fertilization. That this is a very difficult task will be evident when we consider the microscopically small size of the gametophytes, the fact that all the stages must be followed in artificial cultures, and that, in consequence of the time taken in maturing (varying from a few weeks in Laminaria to many months in Chorda), the sexual cells are liberated, one or a few at a time, with long intervals between. It will be evident that the chances are very much against one being fortunate enough to see these stages at the critical time. Even continuous observation would not suffice to guarantee success, for fertilization may be taking place on a slide while it is being examined under the microscope, yet owing to the smallness of the objects the observer may miss it completely. The

[Annals of Botany, Vol. XXXV. No. CXL. October, 1921.] 
cultures, especially if they are old, often have numbers of monads similar in shape and size, and even in the lateral attachment of the cilia, to phaeophycean zoogametes; in some cases ectocarpoid reproductive bodies occur ; this makes it very difficult to be certain of the identity of laminarian antherozoids without having witnessed their liberation.

Over a twelvemonth ago the writer was fortunate enough to be able to fill the gaps in the chain of proofs of the correctness of the theory explained above by observing the liberation of antherozoids, by securing fixed and stained preparations showing the fusion of the sexual nuclei of the fertilization, and, a little later, by actually witnessing the process of fertilization. In response to the urgent requests of botanical friends, a preliminary account of the phenomena is now published, leaving detailed descriptions and drawings to a further series of papers.

The earlier stages in the development of the sexual generations are now sufficiently well known to make it needless to do more than give an outline of the course of events. Although the other British Laminariaceae have been studied, this account will deal only with Laminaria and Chorda.

The pear-shaped zoospore, with its curved chromoplast and its pair of lateral cilia, after a short period of activity comes to rest, becomes spherical, and invests itself with a wall. A tube then grows out from one side of the spore, the chromoplast divides in two, and they, together with the greater portion of the cytoplasm, travel into the germination tube; the nucleus, however, remains behind in the spore-case. The distal end of the tube swells until it becomes much bigger than the original spore; at the same time the nucleus divides, and one of the two daughter nuclei migrates into the enlargement. A wall separates it and most of the original spore constituents from the basal bulb and germination tube, which are now empty save for the second nucleus, now rapidly degenerating, together with occasional traces of cytoplasm. In Laminaria the first division of the nucleus is accomplished as a rule in the spore-case, rarely in the tube. In Chorda the reverse is the rule. In Chorda also the tube is generally much longer than in Laminaria. In these two plants there is no perceptible difference between the early stages of the two kinds of gametophytes.

In Laminaria vigorous cultures show differentiation of gametophytes in a week or less, and new sporophytes may appear in a fortnight. In slow cultures the time taken by the process may be very much longer. In Chorda no fertilization has yet been observed under three months, and very often the time occupied is six months or more.

The young female gametophyte of Laminaria sometimes produces a new sporophyte without further division; in other cases a cell-chain is produced which may even show some amount of branching. These 
growths are very irregular in form and always creep along the bottom. The male gametophyte behaves very differently. It is much smaller than the female: it divides up into much smaller cells, which are more numerous than in the female gametophyte. Sometimes all the cells are short, and the plant is compact ; in others the branches are thin and slightly elongated. Any cell can function as an antheridium. The process commences in the end cells, which become much paler; the wall at the apex of the cell swells greatly and forms a cap or beak; this eventually bursts, and the single antherozoid swims away; ultimately all the cells of the gametophyte become emptied of their contents. One of the first signs of the approaching maturity of a culture is the appearance in it of a few empty terminal cells with openings at their distal ends. Soon after this, the oogonia begin to be differentiated. The one-celled gametophytes, or one or more cells in a multicellular gametophyte, elongate slightly, and become pear-shaped. The wall covering the narrow end becomes very greatly thickened and differentiated into three layers, the middle one showing a laminated structure. The chromoplasts in the narrow end are crowded together, with their long axes parallel to that of the oogonium, and there are evidences of strong internal pressure. A narrow fissure appears in the innermost layer at the apex of the oogonium; this extends outward, but very often before its completion the outer layer bursts and gapes open; the contents are then pressed out through the opening, now much widened. When the whole protoplast has emerged, the thick walls close elastically, and the only evidences of the aperture are a very faint median line and a rim or collar embracing the base of the protoplast, which thus appears seated in a very shallow cup.

One remained long without any clear evidence as to the particular stage at which fertilization was effected: though not probable, it was possible that the antherozoid effected an entrance into the oogonium through the swollen, mucilaginous apex, and that this may have formed the impulse bringing about the liberation of the egg. Now, however, one is able to decide the question, for the eggs have been seen emerging, and, in the cases where antheridia matured at the same time, they have been seen surrounded by active antherozoids. Thus, there can now be no doubt that there is here a differentiated oogonium, and that the single egg produced by it is fertilized after emergence. Fixed and stained preparations often show the gametic nuclei in various stages of fusion. These nuclei cannot be the result of the first division of the oospore nucleus, for, as will be explained later, the appearances presented at that stage are totally different. In one instance the egg had not completely emerged; and its nucleus, elongated and somewhat deformed by pressure, was actually in the narrow neck of the oogonium while the male nucleus had already entered the free apex of the egg. 
In many cases the eggs are observed to have partly disintegrated after emergence. It is not known at present whether this is due to bursting, or to absence of fertilization. While most of the new plants remain attached to the empty oogonium, many become detached and float away. Under natural conditions this probably occurs far more frequently.

The new sporophyte grows rapidly; it is positively heliotropic, so that its direction of growth is quite different from that of the gametophyte, and it is far more regular in its sequence of divisions and in its resulting form. If a preparation be stained with a very dilute solution of polychrome methylene-blue the gametophytes are left uncoloured, but the young sporophytes become at once very prominent owing to the deep pink or purple colour of their cell-walls. The deeper colour occurs in the younger parts; here the minute structure of the wall is very interesting. Further description must be deferred to a future paper.

The first rhizoid makes its appearance early in the form of a rapidly growing, very long protrusion from the basal cell of the sporophyte. This often applies itself in its early stage to the outer surface of the empty oogonium, but, so far, the writer has never observed a case where it entered the oogonium.

The corresponding stages in Chorda, through agreeing with the above in their main features, present interesting differences of detail. The gametophytes are many times bigger than those of Laminaria. They branch again and again in a very irregular manner until they appear like so many miniature bushes. While there is a distinct difference of size between the two kinds of gametophyte, it is never so extreme as in Laminaria. Owing to the long time taken to mature, there is a greater uncertainty and consequent difficulty in securing the critical stages than in the former, and, as it is impossible to obtain pure cultures, the long delay enables other organisms to grow and multiply. A still greater difference is seen in the mode of emergence of the egg. The oogonial wall swells but a very little; the outer layer bursts, and the contents, instead of completely emerging, grow out still enclosed in the extensible inner wall of the oogonium. The emergent part is thus still in communication with the oogonial cavity, and, though the bulk of the contents have migrated out of the latter, a few chloroplasts and granules remain in it. Reinke's well-known figure of a Chorda germling shows this well, but he failed to observe the torn edges of the aperture, which forms a more or less distinct collar or sheath indicating the position of the former apex of the oogonium. It follows from what has been said above that the anchorage of the new sporophyte to the gametophyte is more secure here than in Laminaria. That the enclosing membrane is not very firm is proved by the occurrence of rare cases where the plantlets break off at the collar. For the same 
reason the membrane presents no obstacle to the entry of an antherozoid. (A somewhat parallel instance is observable in Pelvetia.) The mouth of the oogonium in Chorda remains permanently open. The elongation of the young sporophyte is more rapid than in Laminaria, and, in consequence of the multiplication of chloroplasts and the development of their pigments not keeping pace with growth, the whole plantlet looks much paler than the gametophyte from which it has arisen.

A study of the cytology of the different phases confirms the conclusions arrived at on morphological grounds, that in the Laminariaceae we have a case of pronounced alternation of generations, with a great reduction in the gametophytes. The cases in Laminaria where the gametophyte consists of a single cell separated from the zoospore by a single nuclear division make it easy to adopt the suggestion that the so-called oogonia and antheridia in the Fucaceae are sporangia. The systematic position of the group has to be changed; and we now get rid of the anomaly of regarding the alga which shows the highest advance in histological differentiation as a member of the Phaeozoosporeae having only asexual reproduction. The investigation also furnishes material for further consideration of the much-debated question of the relations of Chorda to the other Laminariaceae. 


\section{$2 \mathrm{BHL}$ Biodiversity Heritage Library}

Williams, J. Lloyd. 1921. "The gametophytes and fertilization in Laminaria and Chorda (Preliminary Acount)." Annals of botany 35, 603-607. https://doi.org/10.1093/oxfordjournals.aob.a089779.

View This Item Online: https://www.biodiversitylibrary.org/item/235780

DOI: https://doi.org/10.1093/oxfordjournals.aob.a089779

Permalink: https://www.biodiversitylibrary.org/partpdf/319022

\section{Holding Institution}

Smithsonian Libraries

\section{Sponsored by}

Biodiversity Heritage Library

\section{Copyright \& Reuse}

Copyright Status: Not in copyright. The BHL knows of no copyright restrictions on this item.

This document was created from content at the Biodiversity Heritage Library, the world's largest open access digital library for biodiversity literature and archives. Visit BHL at https://www.biodiversitylibrary.org. 